\title{
Morally Wrong Beauty as a Source of Value
}

\author{
María José Alcaraz León
}

\begin{abstract}
AвSTRACT In this paper I would like to address the problem of the aesthetic value of damaged nature. A variety of arguments have been offered in order to ground the view that we cannot perceive damaged nature as beautiful, at least as soon as we are aware of its damaged condition. These arguments are usually offered in tandem with a view about what the correct appreciation of nature involves and, hence, are often supported by this view.

I will try to show that none of these arguments are compelling and that there seems to be a way of explaining how damaged nature can be beautiful without disposing of the intuition that the awareness of its damaged condition penetrates our perception.

KEYWORDS Natural beauty, aesthetic appreciation of nature, environmental value, environmental damage, moral wrongness
\end{abstract}

\section{Introduction}

Some examples of contaminated rivers or valleys, like the strikingly beautiful landscape of the Tinto River (in Huelva, Spain) or of damaged landscapes resulting from major mining work - like the amazingly colourful hills surrounding the mines of Mazarrón and La Unión (South East Spain) - can provide, I think, some paradigmatic examples of natural beauty. That is, I think that they can be justifiably regarded as beautiful. ${ }^{1}$

However, these cases are also regarded as problematic because they are the result of some sort of ecological damage or alteration which tends to be viewed as an impediment to taking pleasure in their alleged beauty: Either we stop perceiving these sites as beautiful when we know how they really came to look like this - that is, our knowledge of their devastating ecological history penetrates into our perception and prevents us from finding them beautiful, or we refrain from acknowledging their possible beauty by appealing to ecological reasons. Thus, burnt woods, contaminated rivers, and dried valleys cannot - or should not be considered as - beautiful.

There are a number of ways one can approach these problematic cases. I will try to offer an overview of the most prominent views and arguments that have been provided in order to deal with these cases, and I will try to defend the view that damaged nature need not necessarily be perceived as ugly when we are fully aware of its damaged character.

My classification of these views provides some insight into the nature of these cases by dividing them into two categories: On the one hand, there are a number of views which claim damaged nature cannot 
be beautiful because the knowledge that it is damaged penetrates our perception to the point of changing our aesthetic experience of it. Still, it is possible for an advocate of this view to defend the idea that the experience afforded by damaged nature might still be worthy aesthetically. Maybe the ugliness perceived in damaged landscapes is similar to the ugliness that some paradigmatic works of art manifest and that constitutes the source of their value. I will briefly explore this possibility, but I will reject it as a possible explanation for what is at stake in the cases I have in mind.

On the other hand, it is possible to defend the claim that damaged nature might appear as beautiful. This possibility rests upon a Kantian understanding of aesthetic experience. If aesthetic experience is such that no concept whatsoever should determine our response of pleasure or displeasure, ecological considerations should have no bearing upon our aesthetic judgement and, hence, that beauty depends solely upon the form of the natural environment under consideration. However disastrous the ecological history of a particular place might be, if its form is appealing I may have reasons to judge it beautiful. In emphasizing the autonomy and the a-conceptual character of the judgement of taste, it does not need to accommodate the intuition that our aesthetic judgements must be in tune with ecological considerations. In fact, an advocate of the Kantian approach may proclaim damaged nature beautiful precisely because the view leaves the consideration of the environment's damaged condition outside the experience that grounds the aesthetic judgement.

In contrast to these two approaches, I aim at defending the view that damaged nature might be beautiful even if we know that its appearance is the result of some ecological damage and even precisely because we know this. Thus, I endorse the view that knowledge about the object we aesthetically perceive penetrates our perceptual experience and partly informs it. However, I do not think that the polarity we usually attach to the non-aesthetic features or valuable features we also perceive when judging a natural object exclusively determines the polarity of our aesthetic judgement. It may be that in some cases, the perceived damage prevents the object from looking beautiful, but in some others this does not seem to be so, unless we force ourselves to stop seeing the beauty that, prima facie, seems to be there. I think there is some relationship between our knowledge of objects and natural environments from nonaesthetic points of view and our aesthetic experience of them, but this is not necessarily one of complete determinism. Healthy nature may look ugly and damaged nature beautiful. 


\section{Caveat $^{2}$}

Before addressing some of the alternative ways of approaching the problem of the aesthetic value of damaged nature, I would like to answer a possible objection against the very nature of the problem. It could be claimed that the problem is not deciding whether damaged environments can be beautiful or not, but deciding whether or not to adopt the aesthetic stance towards something which should not be perceived, experienced, or assessed in this way. The problem is, it is claimed, that adopting an aesthetic attitude is not even appropriate in these cases. The reason the inappropriateness of the aesthetic attitude is said to be similar to the reason for not taking an aesthetic stance towards war, murder, rape or any other sort of human violence. More generally, aesthetic pleasure seems to be forbidden not only when we encounter real terrible events, but also when we look at photographs or recorded images of events of this sort.

Thus, there seems to be an underlying maxim that inhibits the potential aesthetic pleasure that might be derived from dealing with particularly atrocious scenes, situations, or actions, as if adopting a proper moral attitude towards the scene or the representation would be contrary to perceiving it aesthetically. The implicit acceptance of this maxim seems to be confirmed by many actual troublesome cases in which the mere possibility of an aesthetic attitude has been the subject of much discussion; in fact, in most cases, the aesthetic appreciation of a particular representation has been found morally objectionable.

Similarly, one could think that this incompatibility between the aesthetic attitude and some problematic contents can be also identified in the case that concerns us here. Maybe damaged nature is not the sort of thing that we should address from an aesthetic point of view. Maybe the moral concerns that are triggered by the ecological considerations about a damaged environment are such that no aesthetic attitude seems acceptable.

My view is that, although there is certainly some analogy between the aesthetic appreciation of damaged nature and the aesthetic appreciation of damaged humanity (if we want to put it that way), the analogy is not complete. Not because in both cases the scene is not amenable to aesthetic appreciation - that is precisely the reason why the problem arises in the first place - but because the role our moral concerns play in each case seems different - or at least of a different degree.

It seems to me that the moral concerns we apparently have towards the subjects involved in a terrible situation are not on a par with the 
moral attitude appropriate in cases in which nature is seen as damaged. While there seems to be something morally wrong in perceiving human harm aesthetically - as if contemplating the situation from an aesthetic point of view might itself cause even more harm ${ }^{3}$ - there seems to be no harm in addressing damaged nature as an aesthetic object. The reasons why this asymmetry holds are difficult to specify: maybe in the former case we are dealing with people understood as subjects while this is not the case in the latter, and perhaps this has some relevance in explaining the seeming different moral demands that each situation imposes on us. In this way, there seems to be different moral requirements in each situation, for we do not feel inclined to blame someone who takes an aesthetic attitude towards a natural damaged environment in the way we usually do when assessing someone's aesthetic attitude towards, say, victims of war or victims of the Holocaust.

This asymmetry does not involve completely disregarding the damaged condition of the natural environment that we perceive or that we think it is not regrettable. It only shows that its damaged condition imposes moral concerns of a sort that do not necessary clash with aesthetic pleasure.

After having justified the appropriateness of addressing damaged nature as an object of aesthetic contemplation, I will try to review some of the main views that have dealt with this problem and then go on to offer my own.

\section{Some views about the aesthetic value of damaged nature}

Despite the variety of views on aesthetic appreciation, there seems to be a striking agreement about the impossibility of regarding damaged nature $^{4}$ as beautiful. One of the most recent defenders of this claim has been David E. Cooper in his article "Beautiful People, Beautiful Things." Cooper defends virtue-centrism, a view of the relationship between our moral and aesthetic perception that strongly links the perception of beauty to virtue and vice versa of ugliness to vice. Cooper's main point is that aesthetic perception is intimately linked to the perception of beauty in the human body and that this, in turn, cannot be separated from considerations of the moral character expressed in the features we regard as beautiful; our perception of the human body as expressive of character and its beauty or ugliness are, as it were, of one piece. He tries to distinguish his view from moralist, utilitarian and evolutionary accounts that could similarly ground the idea that beauty cannot be perceived in objects that have been produced through morally wrong means or that 
promote some immoral perspective. In Cooper's view it is not a matter of showing how higher or prior aspects of an object, such as its moral, functional or evolutionary worth, determine its beauty. Rather, beauty is constitutive of the moral character expressed in it.

Cooper does not directly show why there is an essential relationship between perceiving something as beautiful and perceiving it as expressive of some virtue (he tries to make this idea more convincing by elaborating the thought that aesthetic perception is basically linked to the perception of expressive character; in particular, expressive human character.) Instead, he offers a set of arguments that indirectly qualify his idea. I cannot examine each of them in detail here, but I think it is at least worthwhile focussing on one of them; for I think it shows that, contrary to what seems to be Cooper's position, there is an underlying conviction that moral issues are more important than aesthetic ones and, consequently, that only rightness in the former domain can guarantee aesthetic worth in the latter.

Cooper claims that the importance we attribute to beauty in our lives could not be so readily understood if beauty were not "a manifestation [...] of what is most admirable in human beings: their virtues." ${ }^{6}$ To some extent, Cooper is claiming that the value of beauty rests upon the value of "what is most admirable in human beings," and that beauty has its own role in human life from its relation to vices and virtues. This might be a subtle form of moralism, but moralism it is nevertheless. It does not only claim that the significant value of beauty cannot be accounted for unless it is connected to other "most admirable" values, ${ }^{7}$ but also that, as Cooper himself states, "someone cannot authentically regard something as beautiful unless he or she is able to experience it as appropriately related to the manifestation of human virtue."

Although Cooper mostly discusses examples of beautiful works such as music, paintings, buildings, and even ordinary objects, I take his view as a general account of the relationship between the perception of beauty and the perception of other ethical values. In fact, Cooper conceives his own view as being highly comprehensive and claims that "things or objects, whether natural or artefactual, are beautiful only when suitably related to beautiful features of the lived body, and only, therefore, when they are appropriately related to human virtues." ${ }^{\prime 9}$ To this extent, one may claim that it follows from his view that natural beauty must be correspondingly connected to the perception of some kind of expressive character in nature or, at least, that some of its features are to be observed as if they were bodily expressive features of a morally good character. If, 
according to virtue-centrism, the "primary location of beauty is in bodily expression of human virtues,"10 it seems that secondary senses of beauty must be connected to this idea as well. There is, of course a prima facie problem in understanding natural beauty along these lines as it seems less obvious how natural objects or landscapes may exhibit these features in the same way as human bodies or human artefacts do.

However, even granting that perceiving nature in that way is possible, one may still wonder whether this view does not impose an unwarranted condition upon the possibility of nature appearing as beautiful to us. For if beauty and virtue are two aspects of the same perception it seems odd to claim that one can experience a damaged landscape as beautiful. The reason why this may be so is because, given the framework provided by Cooper, there seems to be an unproblematic understanding of damaged nature as a damaged body; a damaged body does not necessarily have to be perceived as embodying the expression of vice, but it is, at least, perceived as the result of some violence or aggression. In fact, we can barely make sense of positive aesthetic judgements about damaged bodies (except, maybe, done within the narrow context of medical admiration; as when we hear about a beautiful wound). For that reason, if a damaged body is not the sort of thing that would appropriately prompt a judgement of beauty, neither would a damaged landscape.

I think Cooper's approach is insightful in the sense that he acknowledges the connections between aesthetic and other (ethical) values, however, he does this to the point of being unable to disentangle them in what we take as paradigmatic cases of aesthetic perception. However, he seems to specify this relationship in a way that makes beauty a sort of manifestation of other more esteemed values. This is why, in his view, damaged landscapes or natural objects could not justifiably be said to be beautiful, even if our aesthetic experience sometimes tells us the opposite.

\section{The Cognitivist strategy}

Another way of making the case for a beautiful damaged landscape problematic has been proposed by authors such as Allen Carlson ${ }^{11}$ and Marcia Muelder Eaton. ${ }^{12}$ The basic idea shared by these authors is that the aesthetic appreciation of nature can - and, indeed, should - be informed by our best scientific knowledge about the natural environment judged. The most prominent defender of this position has been Allen Carlson who has defended the view known as the Cognitivist-scientifc theory of aesthetic appreciation. He claims our aesthetic judgements about natu- 
ral objects and environments cannot be correct unless our perceptual experience is adequately informed by the available scientific knowledge about the objects or environments in question. Once we possess both the accurate knowledge about how some natural item functions and aesthetic sensitivity, we may rightly perceive its features and, hence, derive pleasure from them.

In fact, Carlson is also a defender of the Positive Aesthetics thesis, which claims that all pristine nature is beautiful. ${ }^{13}$ He thinks that the Positive Aesthetics view fits quite nicely with his scientific-cognitivist view about aesthetic appreciation of natural environments. The very nature of scientific discourse - and its structural need to conceptually capture natural species and environments in a way that makes it necessary to appeal to concepts of order, symmetry, structured systems, etc. - provides a reason to think that nature will always look beautiful when viewed through the right scientific categories. It is this underlying search for order, intrinsic to the very constitution of scientific discourse, that gives us a reason to believe that, when perceived in light of the right scientific categories, all particular natural items will look beautiful. They will look aesthetically pleasing because, in perceiving them through the right scientific categories, we will implicitly perceive them as ordered and structured - and these are qualities that we tend to find aesthetic pleasure in. As Carlson puts it: "those qualities that make the world seem comprehensive to us are also those that we find aesthetically good."14 In short, since scientific categories, in their attempt to satisfy categorical order and systematicity, tend to embody the very order and systematicity that usually characterizes aesthetic pleasure; they provide a perceptual frame within which nature appears to us as ordered, systematic and, hence, beautiful. From this it easily follows that perceiving a particular natural item with aesthetic sensitivity and under its adequate scientific description will always produce aesthetic pleasure, and hence the connection between Carlson's scientific-cognitivism and his endorsement of the Aesthetic Positive claim is shown.

Now, it seems easy to see how this view immediately provides reasons for not taking pleasure - aesthetic or other kinds of pleasure - in damaged nature. If beauty judgements result from the proper scientific understanding of the untouched condition of the judged object, devastated or contaminated environments would necessarily be ugly. If healthy nature usually exhibits the order and symmetry embodied in the concepts we use to categorize it, damaged nature, insofar as it looses its structural organicity, will likely lack that order or symmetry, and, hence, it will lack 
the beauty associated to healthy tokens. Devastation will likely have a perceptual correlation in the forms we perceive. Damaged natural environments will not exhibit the order they possessed originally, and their damaged condition will be reflected in their deformed shape. In fact, if notions of symmetry, order, and balance usually play a role in the way we structure the environment conceptually, the expectation would be that contrary notions, such as asymmetry, chaos or lack of balance or form, would be signs of unhealthy environments or species. Thus a wounded plant or animal would probably exhibit some asymmetry in its body that would mar the possibility of taking aesthetic pleasure in it.

I am less certain about what Carlson would say about naturally deformed or corrupted nature. Sometimes the presence of a stronger animal or vegetable species may destroy the conditions necessary for the flowering of other species. Often some magnum storm or hurricane destroys most natural life found in its path. Since these are cases in which the damage has been caused naturally and no human intervention has taken place, should we regard them as ugly? Or are they also a difficult example of how nature can be beautiful? It seems to follow from Carlson's view that if the species that has become dominant - and that has caused the destruction of other species - has been artificially introduced, fed, or promoted by human beings, then the overall results can be considered negative aesthetically speaking. His case seems less justifiable once we pay attention to paradigmatic cases of ugly nature that have not been caused by any human intervention, such as death, decaying animal carcasses or the results of a hurricane. ${ }^{15}$ Although I will not discuss this case here in detail, I think it is a valid question that weakens Carlson's view.

In any case, I think that as Emily Brady ${ }^{16}$ or Malcolm Budd ${ }^{17}$ have, among others, shown, the Cognitivist-scientific view about the aesthetic appreciation of nature faces several problems. Although our scientific common knowledge may affect the way we perceptually address some natural object or environment, this does not always amount to seeing the object in question as beautiful. In fact, Carlson somehow unjustifiably thinks understanding how something is in scientific terms will amount to appreciating it as beautiful.

It seems undeniable that some remarkable species, such as the aye-aye or the star-nose mole, can be good examples of ugly species that remain ugly in spite of the scientific understanding that we might bring to our perceptual experience. Even when one possesses all the relevant knowledge about these natural beings one might not stop judging them as ugly. Similarly, my knowledge that something has been the result of some dam- 
age need not necessarily change my perception of a beautiful object into something ugly. I may perhaps regret the fact that the resulting beauty has some natural disaster behind it, but this does not necessarily modify my perceptual experience of its beauty. As Emily Brady ${ }^{18}$ has pointed out, we should not collapse the notion of aesthetic perception of natural environments into the notion of scientific perception or perceiving an object in light of its correct scientific description. Scientific knowledge may inform our perceptual experience of the environment; however, this should not be taken to imply that the scientific conditions that determine whether some natural being or event is healthy or standard also provide the criteria for what counts as beautiful or aesthetically worthy.

\section{The value of damaged nature as the value of its ugliness}

Another possible way to address the problematic cases I am concerned with in this article is by adopting a strategy from Matthew Kieran's hypothesis in "Aesthetic Value: Beauty, Ugliness and Incoherence." ${ }^{19}$ Kieran has attempted to show that the traditional notion of aesthetic value based upon pleasure leaves little room for paradigmatic cases of modern and contemporary art whose aesthetic value relies precisely on negative features such as ugliness, disgust, or shock. Assuming he is successful in defending this claim, we could extend this view to the aesthetic appreciation of natural environments.

Thus, similarly, one could hold that, damaged nature, although always ugly or unpleasant, is still aesthetically worthy because it is possible to esteem it and find some value attached to its ugliness. Hence, not only is beautiful nature aesthetically worthy; ugly natural environments also deserve aesthetic attention. They might show difficult or negative aesthetic aspects usually lacking in what we take as the paradigmatic aesthetic experience of nature - sunsets, valley views, etc. - but this very lack might constitute its aesthetic strength.

Emily Brady has actually defended the view that natural ugliness can be a reason for preserving some natural environments. ${ }^{20}$ In doing so, she is challenging the underlying assumption of some views such as Positive Aesthetics according to which an aesthetic argument for preservation can only rely upon the consideration of nature as being always beautiful - or at least nature that has not been manipulated. In fact, her view is broader than Positive Aesthetics in one respect, for while the latter only consider beauty as a reason for natural preservation, Brady tries to include negative aesthetic qualities as also providing reasons of this sort. The reason is, again, that there is some value in negative aesthetic 
experiences and, hence, that some action leading to the preservation of a particularly ugly environment can be justified. In short, ugliness can become an aesthetic reason for preservation.

Both Kieran and Brady's views, then, provide possible explanations for the possibility of damaged nature being aesthetically appealing and valuable in spite of its ugliness. Following their strategy - and without denying that they cannot be beautiful given the fact that they are regarded as the result of some harm - our examples could be rewritten so that they become aesthetically worthy in spite of their ugliness - or their being not quite beautiful to us. Notice that their views are not strictly speaking concerned with the issue of whether nature will look ugly because of its damaged condition. Rather, assuming it appears ugly, they provide theoretical tools to inject aesthetic value where only negative experience seemed to be allowed.

This view, however, is still one step short of what I take as our experience of some typically damaged landscapes. I do not think that simply giving some worth to ugly features of natural environments can do justice to what I believe is our experience of some damaged environments. I believe some of these environments can be perceived as beautiful or at least as aesthetically pleasing or interesting. Thus, merely acknowledging some value to negative aesthetic features does not provide the sort of vindicating reason I need in order to show that damaged nature can be aesthetically worthy due to its beautiful character.

\section{Damaged nature as beautiful}

Now, I would like to address two possible ways of accounting for our positive experience of these problematic cases. I have already mentioned that one such strategy can be the Kantian approach. ${ }^{21}$ Following Kant's characterization of the aesthetic judgement and the sort of experience that typically grounds it, we seem warranted in upholding the beauty of these landscapes in spite of their regrettable history of degeneration. Since the judgement is characterized as a-conceptual, disinterested one, there is no reason why we should take into account its damaged condition as part of, or as informing, our perceptual experience and hence our aesthetic judgement. ${ }^{22}$

Therefore, within this framework a beautiful damaged landscape is not a puzzling case, for its damaged condition should not play any role whatsoever in my aesthetic experience of the landscape. If a landscape is said to be ugly it is not, and must not be, by virtue of its ecological health. 
This, however, also falls short of what I would like to defend in this paper. I do not think our experience of the beauty of the landscape must necessarily sacrifice the awareness that it has been generated through ecologically devastating means.

In fact, I agree with the claim that our knowledge of the damaged condition of the landscape penetrates - and must penetrate - our perception. But I do not think the way it informs my perceptual experience of the landscape automatically prevents me from seeing its beauty. What is more, it might even be the case that its former beauty is now tinted by some further significance, for the landscape is now seen in a way which relates those aspects we already appreciated as beautiful with a sort of story that makes salient how they came into their present state. We may still regret that such a beautiful part of the world is the result of processes of degeneration but that does not need to remove our pleasure in its appearance.

My view actually combines some of the insights of the former views. I agree with the cognitivist approach that knowledge penetrates our aesthetic experience of the natural environment in question, but I disagree with it in that if the content of this knowledge reveals that the object has been misused or harmed then our aesthetic judgement must correspondingly be negative. I also sympathise with Cooper's view that the perception of beauty is linked to some moral notions. However, I think, one may adopt two different attitudes towards a damaged landscape that, respectively, reveal two different relationships between the moral and the aesthetic. The first one - which I think is the wrong one - tends to make the aesthetic dependent upon the moral; so that, if something is shown to be morally wrong, or the result of a moral wrong, then it is perceived as less beautiful, or as straightforwardly ugly. The second, the one I endorse, does not take morality to dictate the aesthetic result. It may inform the aesthetic experience, so that it also becomes a way of revealing the (moral) history of the environment judged, but it does not necessarily transform beauty into ugliness.

How then, shall we understand the relationship between the aesthetic quality revealed in an experience of a damaged landscape or environment and other non-aesthetic considerations, such as ecological or moral ones? It seems to me that any sort of link that we aim to establish that makes the aesthetic dependent upon the moral, the scientific, or the ecological, threatens the autonomy of the aesthetic judgement. If our identification of positive and negative values in morality is sufficient to determine the aesthetic value of a particular object, landscape or environment, 
we get close to rejecting the necessity of an aesthetic experience in order to reach an aesthetic judgement. Thus, simply pointing to a negative ecological reason would be enough to claim that the corresponding aesthetic judgement will be negative too. However, I think that, even if we think that other non-aesthetic considerations might enter, inform, and determine our aesthetic experience, the autonomy of the judgement of taste must be preserved. The crucial point is to understand this relationship as one in which the determination is not overriding. For example, the thought that the appearance of the Mazarrón Mines landscape has been produced through years of mining work and exploitation penetrates my perceptual experience so that the colours, shapes, and forms that I perceive bear on that history. I do not simply see a beautiful arrangement of colours; I see the traces of different strata that have been carved and removed. I may even imagine what kinds of work were undertaken in order to extract the minerals (mainly, silver, lead, zinc, and iron). All these thoughts that correspond with the actual history of the place can be an important constituent of my experience and they add colour and give significance to all of them.

If the aesthetic appreciation of nature must be such that we appreciate it as nature, as what it is, it seems then that all the information that explains or is related to the appearance that particular landscape has is a key element of the experience this landscape is to afford. However, the positive or negative judgement about the history behind a particular landscape does not in itself determine the quality of our aesthetic experience and the positive or negative quality of our aesthetic judgement.

We can, then, claim that as well as looking at a work of art with the appropriate information about its style, period of production, technique, etc., that might be necessary to properly grasp its aesthetic value, we need to take into account the particular history that a particular landscape has. If I do not know, for example, that a particular portrait was produced with the intention of making fun of the person portrayed, I might probably miss some aesthetic aspects of the portrait. However, knowing that there was an intention to mock someone (and maybe, judging that this sort of intention might be morally wrong) does not lessen the work aesthetically. Similarly, knowing that a history of exploitation and degradation lies behind the appearance that I perceive frames my perceptual experience in that particular way, but it does not straightforwardly determine whether the resulting aesthetic experience is positive or negative. As in art, experience has the last word in the aesthetic appreciation of nature. 
Moreover, not only do I think our aesthetic experiences of environmental objects are connected with other - maybe ecological - considerations, indeed, I propose that they may even be revelatory of such considerations: aesthetic experiences may highlight those aspects with a new strength. Thus, our awareness of the landscape as damaged is, in turn, partly informed through the aesthetic experience that reveals it as sublime, beautiful, or astonishing; and in that sense, it is precisely through aesthetic attention that our overall experience becomes insightful in a broader sense.

The aesthetic sentiments become, in this way, useful tools to focus our attention upon features that might be revelatory of the particular history behind the configuration of an environment and to become sensitive to aspects of that environment.

\section{Final remark: sublime rather than beauty?}

There might be a final point worth considering given the plausibility of an aesthetic mischaracterization of some of the examples of damaged nature. It could be claimed that these sorts of cases are better characterized in terms of the sublime rather than the beautiful. ${ }^{23}$ Even if the damaged condition of the burned wood does not turn the aesthetic experience into one of ugliness, it seems odd to simply claim that we experience the burned wood as beautiful; rather, the appropriate feeling towards such landscapes is one in which a certain mix of negative and positive feelings is involved -one that can probably be better characterized as sublime.

I think this is a sound possibility regarding some of the examples one may think of. After all, there is a long tradition within the aesthetic category of the sublime that confirms the adequacy of this particular sentiment for a number of landscapes.

This proposal could then be understood as a possible accommodation within a particular aesthetic experience of the negative moral quality involved in any damaged landscape. Thus, describing the experience of damaged landscapes as sublime instead of beautiful will accommodate both the intuition that there is something odd in taking pleasure in a damaged environment and the belief that some damaged environments possess indisputable aesthetic value.

Nevertheless, I think there are no reasons for a priori ruling out the possibility of finding different damaged landscapes as possessing different aesthetic qualities, among them beauty. First, the consideration of other possible aesthetic categories - especially those essentially connected to negative feelings, that can help us to grasp in a better and finer 
way the sort of aesthetic experience one may have in paradigmatic cases of damaged natural environments - still leaves open the possibility of cases of beautiful damaged nature. Second, I do not think a set of criteria that determine which cases are better described as sublime, beautiful or picturesque can be offered in a non-problematic way. In fact, trying to offer these criteria will lead to the former attempt - which I rejected on the basis of aesthetics' autonomy - of finding correlations between moral reasons (or other non-aesthetic features) and aesthetic qualities. I think whether a particular landscape looks sublime, beautiful, amazing, or weird and wonderful is a matter that can only be settled by experiencing the landscape or environment in question. Again, I think that this experience is not disconnected from the relevant thoughts about what we are experiencing. These thoughts inform and frame my perceptual experience, even though I cannot exclusively rely upon them in order to determine the aesthetic quality of a particular landscape or natural environment.

Certainly, our morality enters our aesthetic sensibility but - if aesthetic autonomy holds - it does not do so in the form of an absolute authority.

\section{Notes}

1. Although I present the problem in terms of the aesthetic category of beauty, I think it can be thought in terms of other aesthetic categories. The reason for focusing on beauty is that this provides a clear idea of what sort of problems one may face when addressing the possibility of finding some aesthetic pleasure in damaged environments.

2. I owe this suggestion to one of the members of the audience at the EAA conference in Lahti, June 2010.

3. The reason why we think taking aesthetic pleasure in these cases might be harmful is because this might inflict shame; also, this kind of response can be a sign of incomprehension or disrespect. Nature lacks the subjectivity necessary for these sorts of relationships to take place and, therefore, the character of the aesthetic pleasure we may take in it is also different in this respect.

4. I will not differentiate between damaged nature that has become so due to human action and naturally damaged nature.

5. David E. Cooper, "Beautiful People, Beautiful Things," British Journal of Aesthetics 48 , no. 3, July 2008 , pp. 247-26o.

6. Cooper, p. 253.

7. Furthermore, I do not think this argument can persuade someone who is already convinced that beauty as such is a value and that, therefore, there is no 
need to find a further or higher value with which beauty is connected so that its significant value in human life is guaranteed.

8. Cooper, p. 255 .

9. Cooper, p. 247.

10. Cooper, p. 247

11. Allen Carlson, "Appreciation and the Natural Environment," in The Aesthetics of Natural Environments, eds. Allen Carlson and Arnold Berleant (Toronto: Broadview Press Ltd., 2004), pp. 63-75.

12. Marcia M. Eaton, "The Beauty that Requires Health," in Placing Nature: Culture and Landscape Ecology, ed. Joan Nassauer (Washington, DC: Island Press, 1997).

13. He claims: "the natural environment, insofar as it is untouched by man, has mainly positive aesthetic qualities; it is, for example, graceful, delicate, intense, unified, and orderly, rather than bland, dull, insipid, incoherent, and chaotic." Allen Carlson, "Nature and Positive Aesthetics," in Nature, Aesthetics and Environmentalism: From Beauty to Duty, eds. Allen Carlson and Sheila Lintott (New York: Columbia University Press, 2008), 211-237, at p. 211.

14. Carlson, pp. 229-30.

15. After all, if we stick closely to his view that all pristine nature is beautiful, he should be committed to the idea that rotten animals and destroyed environments after a hurricane should be seen as beautiful.

16. Emily Brady, "Ugliness and Nature", Enrahonar: quaderns de filosofia 45 (2010), pp. 29-42.

17. Malcolm Budd, The Aesthetic Appreciation of Nature: Essays on the Aesthetics of Nature (Oxford: Clarendon Press, 2002). Other authors such as N. Carroll or E. Brady have also rejected Carlson's cognitivism on a similar basis.

18. As she puts it: "I'm not setting up a dichotomy between aesthetic experience and knowledge; knowledge of all kinds can undoubtedly inform and enrich aesthetic experience. Rather, I'm trying to distinguish between aesthetic and scientific appreciation." Brady, p. 32.

19. Matthew Kieran, "Aesthetic Value: Beauty, Ugliness and Incoherence," Philosophy 72 (1997), pp. 383-99.

20. Brady, 2010.

21. I am aware that what I term the "Kantian view" might not strictly speaking be Kant's point of view over the matter. I use this label because I think it conveys two main points, which I think are central for the view I identify here. The first is that, for Kant, aesthetic judgement was founded in an experience of the form of the object; and the second that the experience of the aesthetic quality of this form is independent from any concept we might have of the object, that is, aesthetic experience is a-conceptual. 


\section{María José Alcaraz León}

22. This conclusion might seem odd given the moral significance Kant gave to our appreciation of natural beauty and the role he assigns to it in our apprehension of moral goodness. However, as P. Guyer has extensively shown Kant's view about natural beauty as a symbol of morality that does not undermine the distinctive freedom that characterizes the judgement of beauty. In fact, it is precisely in virtue of this freedom that aesthetic experience can be a symbol of morality, i.e., a symbol of our freedom. See Paul Guyer, Kant and the Experience of Freedom: Essays on Aesthetics and Morality (New York: Cambridge University Press, 1993).

23. I owe this suggestion to one of the members of the audience at the EAA conference in Lahti, June 2010. 